\title{
As MÚLTIPLAS FUNÇốES SINTÁTICO-SEMÂNTICAS DO ITEM ONDE No PoRTuguÊS Do BRASIL: UMA ABORDAgEM FUNCIONALISTA PARA O ENSINO
}

\author{
ELISANDRA FILETTI ${ }^{*}$
}

\begin{abstract}
Resumo
O presente artigo discute a importância dos estudos funcionalistas para o ensino de língua portuguesa e toma como elemento de análise os usos do item onde na produção de texto de alunos do Ensino Médio. A escolha dessa vertente teórica dá-se pelo fato de que essa teoria permite observar a língua em uso, verificando como o falante se adequa às situaçôes de fala, à situação comunicativa. Em sala de aula, a análise da língua em uso permite não somente o reconhecimento dos variados usos da língua portuguesa, mas também a compreensáo das regras sintático-semânticas que determinam o desempenho lingüístico dos falantes.

Palavras-chave: Funcionalismo, língua em uso, multifuncionalidade, ensino.
\end{abstract}

The multiple syntactic-semantic functions of the item onde in Brazilian Portuguese: a funcionalist approach for teaching

ABstract

The present article points the importance of the functionalist's studies for the teaching of portuguese language and takes the uses of the item onde as an element of analyses in the texts produced by High School students. The choice of this theoretical approach was made because this theory allows to observe the language in use as well as verifying how the speaker adjusts to the situations of speech in a communicative situation. In classroom, the analysis of the language in use not only allows the recognition of the varied uses of the Portuguese language, but also the understanding of the syntactic-semantic rules that determine the linguistic performance of the speakers.

KeYwords: Functionalism, language in use, multifunctionality, teaching.

\section{INTRODUÇÃo}

$\mathrm{O}$ ensino de língua portuguesa tem passado por muitos questionamentos ao longo das últimas décadas. Muitas teorias lingüísticas têm apresentado resultados que amparam, de certa forma, o ensino de língua, como a Lingüística Textual, a Gramática Funcional, entre outras. A mudança de

Professora de Língua Portuguesa do Centro de Ensino e Pesquisa Aplicada à Educação - Cepae - da Universidade Federal de Goiás. Mestre em Lingüística (UFMG). E-mail: elisandra.filetti@uol.com.br 
enfoque dado ao ensino de língua privilegia a língua em uso e a interação dos falantes quanto à concepção de ensino trazida por essa mudança de enfoque.

Ao considerarmos o ensino de língua materna a partir dos enunciados nela produzidos, ampliamos consideravelmente as possibilidades de compreensão dos mecanismos que regem uma língua. No entanto, como educadores, deparamo-nos com dificuldades que residem no fato de que as escolas, de uma maneira geral, mesmo tendo conhecimento dos avanços na pesquisa lingüística, ainda ensinam língua portuguesa a partir das noçóes de uso, de certo ou errado, tradicionalmente defendidas pela gramática tradicional. Constatando essa dicotomia entre os avanços teóricos e metodológicos, propostos pela Lingüística e pelo ensino de língua materna, os professores se deparam com a dificuldade de entenderem que norma lingüística ensinar, uma vez que é difícil substituir uma prática de ensino de língua tão enraizada por outra que considera a pluralidade lingüística. Surgem, então, dúvidas da seguinte natureza: como ensinar a língua padrão e, ainda assim, contemplar a diversidade lingüística, a língua em uso?

A fim de esboçar essa discussão acerca da língua em uso tomo como objeto de pesquisa as ocorrências de onde como um elemento relacional que vem apresentando um caráter multifuncional no Português do Brasil (PB). Essa ocorrência variacional do item onde tem se mostrado bastante produtiva, tanto no âmbito da fala quanto no da escrita. Para desenvolver a discussão aqui, reporto-me a alguns trechos de textos de alunos do Ensino Médio do Centro de Ensino e Pesquisa Aplicada à Educação da Universidade Federal de Goiás (Cepae-UFG).

É importante ressaltar que não desejo defender, com este artigo, que o ensino da variante padrão seja abolido da escola, nem apresentar "receitas" para o ensino de língua portuguesa, pois acredito que a condução do processo de ensino-aprendizagem de uma língua segue seu próprio curso, dependendo das situaçóes que envolvam tal processo. Assim, pretendo discutir algumas contribuiçôes teóricas da Gramática Funcional para o ensino de língua portuguesa.

\section{A ANÁLISE LINGüístiCA E O ENSINO DE LÍNGUA PORTUGUesa}

O ensino de língua materna no Cepae é orientado por uma perspectiva contextualizada do uso da linguagem que tem em Bakhtin (1995) uma primeira orientação epistemológica. Assim, considerando que os enun- 
ciados lingüísticos são produzidos a partir de situações de fala, todo trabalho desenvolvido com a língua tem sido direcionado por uma abordagem que considera a língua em uso, ou seja, é o texto o objeto a partir do qual são analisados e discutidos os fatos lingüísticos de natureza escrita e oral. Nesse sentido, o trabalho com a estrutura lingüística (Morfologia, Sintaxe e Semântica) envolve um questionamento a respeito das funçōes lingüísticas envolvidas na produção de textos, isto é, no momento em que o falante usa a língua, em suas mais variadas condições de produção.

O que se tem de perceber é como fazer do ensino de língua mais que simples categorização de classes gramaticais e de funçōes sintáticas, além disso, reconhecer o que é um texto e qual o papel que ele deve ocupar no ensino de língua. O problema não está em ensinar, mas no "como" ensinar, já que a gramática, de acordo com os PCNEM (1999), apresenta-se como mais um dentre os vários conteúdos que, juntos, constituem a disciplina LP e não como o "único". (Rauber, 2005, p. 31-32)

Ensinar uma língua materna requer do professor, principalmente, a habilidade de reconhecer que é importante valorizar os conhecimentos de um falante sobre sua língua, considerando que a situação de ensinoaprendizagem não é linear, muito menos previsível. $\mathrm{Na}$ sala de aula, o professor trabalha com um número quase infinito de situaçóes comunicativas: falantes oriundos de lugares diferentes, com histórias diferentes. Sendo assim, o ensino de língua não pode se furtar a considerar tais nuances no processo de aprendizagem e exercício da língua pelos sujeitos envolvidos.

A sala de aula torna-se então um lugar de convergência, mas, sobretudo, de contradições, pois a língua, assim como seus falantes, apresenta-se heterogênea e está sujeita às influências externas, ambientais. Analisar a língua em uso, no processo de aprendizagem da língua materna na escola, é entender que a linguagem se constitui de múltiplas situações comunicativas com propósitos próprios.

Umas das maiores preocupações do ensino de língua materna reside em relacionar, por um lado, uma tentativa de uniformização do uso da língua, padronizando-a, como propóe a Gramática Tradicional e, por outro, valorizar e estudar a variedade lingüística, que é própria da natureza de qualquer língua natural e constitui outra faceta de uso dessa mesma língua. 
160 Revista Solta a Voz, v. 18, n. 2

As discussóes acerca de que língua se deve ensinar em sala de aula estão longe de ser finalizadas, mas o debate tem demonstrado que não se pode furtar em ensinar a língua portuguesa, por exemplo, distante de um universo de novas práticas lingüísticas, novos usos. Essas manifestações da língua devem ser incorporadas à reflexão lingüística em sala de aula, no sentido de ampliar as condições do estudante/falante em pensar a língua como possibilidades infinitas de constituição de sua subjetividade. Esse debate tem estado subjacente às discussóes que envolvem a aplicação dos conhecimentos provenientes das várias correntes lingüísticas e que é transposto neste artigo a fim de justificar a pertinência de estudos que privilegiem o estudo e o ensino contextualizado de língua.

\section{Os FATOS DA LÍNGUA E AS ABORDAGENS FORMALISTAS E FUNCIONALISTAS}

A concepção de língua que subjaz ao ensino de língua adotado pelo Cepae é, portanto, orientada por um trabalho de caráter funcional, que privilegia a língua em uso, pois considera como importante característica a contextualização lingüistica, assim como a reflexão sobre o uso a partir dos fatos da linguagem.

Essa concepção de ensino de língua reconhece que a produção textual é uma questão de gramática - como estrutura lingüística - e optar por essa posição decorre de um trabalho de pesquisa e dedicação ao estudo das teorias de linguagem que vem sendo desenvolvidas desde o século XX. A compreensão acerca do conceito de língua e linguagem difere de acordo com o olhar atribuído a esses objetos, assim como esse olhar tem sido determinado pelo contexto sócio-histórico que envolveu o desenvolvimento das diversas teorias lingüísticas. Do mesmo modo, os princípios que norteiam a abordagem teórica de língua desencadeiam mudanças na ação pedagógica referente ao ensino da língua materna.

Durante todo século XX coexistiram teorias sobre a linguagem; muitas delas divergem quanto ao recorte epistemológico que fazem de seu objeto, mas contribuíram significativamente para o modo como o ensino de língua tem tratado os fatos de linguagem. Citarei aqui a abordagem gerativista de Chomsky (1965), por considerar a língua como um constructo abstrato, de caráter mental, e a abordagem funcionalista de Simon Dik (1989), que entende a língua como um sistema de uso condicionado pela integração dos componentes da estrutura lingüística e pragmática. 
Para a Gramática Gerativa, a mente apresenta um papel preponderante na aquisição de uma língua particular, como um sistema computacional que atribui ao falante uma capacidade mental inata que lhe permite comunicar-se. Ao se preocupar exclusivamente com o módulo mental, que capacita o homem a exercer a linguagem, a gramática gerativa evitou qualquer análise de fundo interacional, social. A ênfase dada ao estado inicial da mente/cérebro tornou-se seu objeto de estudo, e não o uso social da língua, como quer outras abordagens teóricas de cunho social e interacional, como a Gramática Funcional (Halliday, 1985; Dik, 1989, 1997).

A teoria funcionalista contrapóe-se à perspectiva formalista de Chomsky, pois se preocupa com a inter-relação dos sistemas de competência e de uso da língua (Cf. Halliday, 1985; Dik, 1989, 1997; Neves, 1997, 2002, 2003), por isso será a perspectiva adotada neste trabalho. Segundo a Gramática Funcional (GF), a língua é um sistema não-autônomo, dinâmico, em que as estruturas gramaticais se inter-relacionam e são moldadas pelo uso que o falante faz dessa língua.

Embora sejam correntes lingüísticas contrárias quanto ao objeto de estudo, é importante ressaltar as contribuiçóes que ambas as teorias tem gerado para a discussão e o crescimento da Lingüística como ciência. É importante ressaltar, ainda, que o ensino de língua, em muitos casos, nos coloca questionamentos que ultrapassam as linhas demarcatórias das diversas teorias lingüísticas existentes, e, por isso, me parece adequada esta discussão.

Para entendermos a complexidade pela qual o falante passa ao adquirir uma língua, é necessário buscar nas teorias existentes suportes teóricos e metodológicos que possibilitem entender e conduzir o processo de ensino de uma língua. $\mathrm{O}$ uso do texto como objeto de análise contextualizado proporciona ao educador uma reflexáo mais acurada da relação entre os níveis estruturais da língua e a relação que se estabelece entre os falantes na comunicação, proposta que se aproxima da perspectiva funcionalista de linguagem adotada neste artigo.

\section{Gramática Funcional aplicada ao ensino de Língua portuguesa}

Para a Gramática Funcional (GF) a linguagem se constitui na interação social e tem, nos trabalhos de Halliday (1985), Givón $(1979,1995)$ e Dik (1989, 1997), a apresentação de seus princípios teórico-metodológicos. Para essa concepção teórica, a língua é fruto de uma competência comunicativa 
162 Revista Solta a Voz, v. 18, n. 2

que permite ao usuário construir e interpretar os enunciados lingüísticos e usá-los de maneira satisfatória. A noção de competência comunicativa implica a de função, no sentido de que o falante atribui à linguagem um papel, o que implica o caráter de universalidade e variabilidade lingüísticas. Essas funções determinam o comportamento lingüístico e as metafunçóes conceituadas por Halliday (1973), que são:

a) ideacional - tem como finalidade a manifestação de conteúdos que estejam ligados às experiências que possuímos do mundo concreto, real ou dos processos mentais e abstratos;

b) interpessoal - relaciona-se aos os usos que os falantes fazem da língua para expressarem suas relaçóes sociais e pessoais;

c) textual - essa função estabelece uma relação entre falante e interlocutor de forma a distinguir e relacionar discursos.

$\mathrm{Na}$ interação comunicativa essas funções podem ocorrer simultaneamente, organizando o próprio ato comunicativo, bem como os papéis dos falantes nessa situação interativa. Nesse sentido, a gramática de uma língua expressa a relação entre os fenômenos que descrevem as experiências que temos no mundo exterior, assim como as relaçóes sociais que nos permitem organizar os eventos comunicativos que se manifestam materialmente por meio do discurso. A inter-relação dos componentes ideacional, interpessoal e textual promove o funcionamento do sistema lingüístico como um todo, manifestando as intençóes comunicativas dos falantes quan to à organização da informação lingüística, da interação entre os falantes, assim como dos sentidos possíveis pretendidos por esses falantes.

Assim, a teoria funcionalista permite uma aplicação de seus princípios ao ensino, o que não ocorre, a priori, com outras teorias lingüísticas de cunho formalista. A teoria da gramática funcional concebe a língua como um sistema dinâmico, cuja estrutura gramatical está subordinada a regras pragmáticas, além das sintático-semânticas que refletem o dinamismo do sistema lingüístico-interacional. Nesse sentido, o sistema lingüístico é visto como um conjunto infinito de expressóes e sentidos possíveis que permitem ao falante optar, de acordo com a situaçáo comunicativa, pela formação lingüística mais adequada.

Alguns autores como Simon Dik (1989, 1997) e Halliday (1985), em seus construtos teóricos, consideram as funçóes dos itens lingüísticos 
sob um olhar mais amplo a respeito da linguagem, ponderando que uma teoria adequada de descrição e explicação lingüística deve ser desenvolvida a partir da interface dos componentes fonológico, morfossintático, semântico e pragmático, evidenciando um sistema de usos da língua. Assim, um modelo como este permite uma compreensão da multifuncionalidade do sistema lingüístico.

Segundo Dik (1989), as regras da gramática de uma língua devem ser explicadas em termos de sua funcionalidade, principalmente no que se refere ao modo como são usadas por seus falantes, bem como sua multifuncionalidade, ou seja, a interrelação dessas funções e a organização hierárquica dos níveis lingüísticos ilustram a criatividade lingüística dos falantes. Dessa maneira, para a GF, de acordo com Dik (1989), o componente pragmático, por exemplo, é responsável por integrar os componentes semântico e sintático, e a interface desses componentes é fundamental para o estabelecimento das funçôes lingüísticas ou dos Estados de Coisas - construto que define toda e qualquer concepção que diz respeito às coisas existentes no mundo e que são identificadas pelas relaçóes de predicação. O Estado de Coisas possui relação direta com a capacidade de o indivíduo formular conceitos mentais ou reais sobre as coisas do mundo em um dado momento e época.

A GF busca explicar como as expressões lingüísticas são estruturadas por meio de regras e princípios, obedecendo à função e ao uso que o falante faz delas, sendo que esses princípios e regras devem estar sujeitos a regras de uso que determinam a interação verbal (cf. Neves, 1997; Castilho, 1998). A partir de tais princípios é possível afirmar que a GF fornece subsídios teóricos que dão suporte ao ensino de língua, especialmente com o exercício de reflexão sobre o processo de aquisição e sistematização da escrita em sala de aula.

Essa abordagem pensa a gramática da língua como um campo em que as necessidades discursivas tomam forma, sendo a gramática o local em que o discurso se adapta às regras de uso. Isso significa que o discurso se submete a princípios como o da iconicidade, que prevê uma conexão não-arbitrária entre forma e função na gramática de uma língua, da ordem dos constituintes, da marcação dos itens gramaticais etc. Conseqüentemente, a aplicação das regras gramaticais constitutivas desse discurso estão intimamente relacionadas ao uso lingüístico, constituindo, assim, um ciclo contínuo. 
164 Revista Solta a Voz, v. 18, n. 2

O trabalho de Rauber (2005) é uma ilustração das possibilidades de uma abordagem funcionalista aplicada ao ensino. $\mathrm{O}$ autor defende que uma visão funcional, interacional, de abordagem lingüística estabelece uma nova significação para o tratamento dado ao ensino de língua portuguesa, uma vez que apresenta a correlação entre os componentes estruturais da gramática e o componente pragmático.

$\mathrm{Na}$ seção que segue serão discutidos alguns aspectos gramaticais relativos ao uso do item onde, encontrados em textos de alunos do Ensino Médio e que fornecem questionamentos a respeito da maneira como o ensino de língua portuguesa pode ser desenvolvido sob uma perspectiva funcionalista.

\section{Os usos do onde no Português do Brasil}

A recorrência do item onde, em seus mais variados empregos, nos textos selecionados para análise neste artigo, motivou uma reflexão mais atenta às condiçóes que permitiam a esses estudantes estabelecer novos usos para esse item, observando como as forças gramaticais atuam no movimento e estabelecimento das estruturas lingüísticas.

$\mathrm{O}$ item lexical onde, no Português do Brasil, parece apresentar um caráter "multifuncional” (Souza, 2001; Neves, 1999). Além disso, atua como um elemento coesivo, estabelecendo a referência no texto e promovendo o encadeamento de idéias nas seqüências argumentativas. Algumas gramáticas normativas afirmam que onde carrega uma essência locativa e outras, como a de Bechara (2000), descrevem a ocorrência híbrida do termo, ora advérbio, ora pronome.

[1]

a. A rua onde se encontra a papelaria fica na esquina com a rua 3.

b. O hotel onde ficarei é bastante confortável.

Em sua origem latina, o termo ondelunde era marcado por seu valor locativo, embora existam alguns casos em que se apresentava também como temporal (cf. Cunha, 1994), o que parece indicar desde já sua natureza híbrida. Segundo Neves (2001, p. 558), como advérbio onde, além de referir-se a lugar, indica permanência. Já como pronome relativo, "onde vem sendo usado sem referência a lugar, equivalente a em que, no 
Revista Solta a Voz, v. 18, n. 2165

qual, uso condenado pela norma padrão". Como se pode observar no exemplo [2]:

[2]

A ediçẫo de 16 de abril traz um artigo sobre a lógica "fuzzy", teoria matemática onde elementos podem pertencer apenas parcialmente a conjuntos. (FSP)

Esses usos, muito encontrados também em textos escolares, conduzem ao seguinte questionamento: o item onde está passando por um processo de perda semântica, sendo reajustado pelo sistema lingüístico? Este item está perdendo seu valor de referenciação?

Alguns aspectos devem ser considerados no uso de onde como, por exemplo, na frase:

[3]

a. A escola onde freqüento é bastante interdisciplinar.

b. A escola que freqüento é bastante interdisciplinar.

Neste caso, o uso do item onde retoma o sentido de lugar já expresso em "A escola", sendo usado como um pronome relativo. Esse uso, muito comum, é rejeitado pela norma padráo, uma vez que a transitividade do verbo "freqüentar" exige um objeto direto, sendo, portanto, o termo "que" indicado em [3b].

Segundo a gramática normativa, as oraçóes subordinadas nas quais o onde ocorre são as subordinadas adjetivas explicativas e as restritivas, sendo este um elemento que retoma o sentido expresso pelo sintagma nominal "A escola", e, ao mesmo tempo, estabelece a relaçáo subordinante da oração que encabeça. Assim, o item onde pode ocorrer na oração com ou sem um antecedente. Nesse sentido, pode carregar traços locativos ou apresentar ocorrências de natureza mais abstrata como a temporal, discursiva etc.

Segundo Souza (2001), o estudo de oraçôes com onde, em especial as relativas padrão, é estruturado de maneira que esse item expresse um valor primeiro de espaço físico; já as relativas não-padrão são usos do onde que equivalem a usos com valor de espaço abstrato, nocional, de tempo e de posse. Alguns desses usos têm sido encontrados nos textos dos alunos que são analisados neste artigo, o que corrobora a idéia de que o item onde apresenta um dinamismo recorrente tanto na fala como na escrita, estabelecendo outros 
166 Revista Solta a Voz, v. 18, n. 2

usos sintáticos com valores diferenciados no processo de referenciação textual, ora marcados no interior do texto, ora exteriores a ele. Nesse sentido, o uso de onde com funçóes sintáticas distintas parece demonstrar a uma alternância expressando contínuum:

espaço físico (advérbio de lugar) > valor relativo (pronome relativo) > marcação de espaço abstrato (marcador temporal) $>$ marcador discursivo

A multiplicidade de ocorrências de onde foi encontrada como um elemento produtivo nas produçóes textuais de alunos do Cepae do $2^{\circ}$ Ano do Ensino Médio. Por hora, apresento três trechos para análise, dentre vários coletados, devido à restrição de espaço que este texto apresenta.

[4]

A escravidão um mal que nos assombra desde o passado. No meio histórico, nosso país foi construído pela escravidão, onde [quando] portugueses traficavam negros das regióes centro-oeste e oeste da África para trabalhar aqui, em ofícios degradantes e em condiçôes subumanas, com alimentação precária.

[5]

[...] Sociedade onde [que] não se difere os direitos entre etnias (brancos, negros, etc), uma frase banal para um país (Brasil) que cerca de $80 \%$ dos presidiários são negros, $5 \%$ das vagas das faculdades são para negros e em um país que a maior parte da população é negra. $\mathrm{O}$ racismo é realidade ainda nos dias de hoje? Si é uma grande realidade tanto no Brasil como em outros países que dizem viver em uma democracia racial.

[6]

[...] A autora também utiliza a carta de Pe. Manoel da Nóbrega a El Rei D. João [referência ao romance Desmundo, de Ana Miranda], onde ele fala sobre a falta de mulheres e pede ao Rei que enviasse órfâs brancas portuguesas para que casassem com os homens daqui.

No primeiro trecho, a palavra "escravidão" é o referente ao qual se liga o item onde. Nessa retomada, onde se refere à "escravidão" como uma etapa da História do Brasil, indicando o período durante o qual o processo de tráfico negreiro foi mantido. Já no segundo trecho, a palavra "sociedade" é também referente de onde, mas expressa outro tipo de relação: de um local 
abstrato, como um marco espacial, virtual, localizado no ambiente textual. Por fim, no último trecho, o item onde, como relativo, evidencia uma clara ligação com a palavra "carta", podendo ser substituído pela expressão "na qual", indicando o sentido de a carta constituir uma espécie de lugar textual, utilizado pelo Pe. Manoel da Nóbrega para solicitar ao Rei D. João o envio de jovens ao Brasil Colônia.

A multiplicidade de usos do item onde indica uma polissemia, o que por vezes pode, ao longo do tempo, alterar as relações de referência estabelecidas por esse item no espaço discursivo. Se a hipótese de que o item onde apresenta uma multiplicidade de funçóes se verificar no Português do Brasil, o ensino de língua deverá incorporar essa discussão de forma a trazer a estudantes e professores respostas, ao menos, sobre a variedade de comportamentos gramaticais no sistema lingüístico. Mesmo que o ensino tradicional de língua tenha como um de seus objetivos o ensino da norma escrita padrão, os textos de circulação nacional, inclusive os literários, têm trazido exemplos gramaticais que evidenciam a multiplicidade de usos de onde.

Segundo Ferreira (2003, p. 75), no português contemporâneo o item onde tende a atualizar outros sentidos diferentes do sentido de lugar comumente atribuído a ele. Esses outros usos revelam um valor anafóricodiscursivo de espaço e, em alguns contextos, chega a perder totalmente o sentido de espaço físico, passando a um marcador discursivo vazio de sentido, funcionando como um elemento coesivo que apenas mantém a continuidade do discurso.

Essa pluralidade de usos e funções do item onde não parece demonstrar uma adulteração do sistema referencial do português, pois não interfere no estabelecimento da referência anafórica ou catafórica, apenas introduz outras noçóes como a temporal e a extra-oracional. Esse parece ser um indício de que a língua é fluida e permite uma variação tal de formas e sentidos que determinam a riqueza da organização lingüística. À escola cabe direcionar a maneira como esses usos são realizados, estabelecendo sempre um paralelo entre usos canônicos e usos novos de uma forma lingüística. Assim, o aluno poderá perceber a vivacidade do sistema lingüístico em seus mais amplos domínios.

Essa tarefa é árdua, uma vez que o ensino de língua não se restringe apenas ao ensino das estruturas lingüísticas, mas, sobretudo, enfoca o estudo e a análise dessa estrutura formalizada nos diversos gêneros discursivos, como bem propóe os PCN (1997), assim como os efeitos de sentido que 
envolvem essa organização lingüística. Para assumir essa tarefa é importante pensar o ensino de língua mediante estratégias eficazes para seu uso: o desenvolvimento da capacidade de articulação clara da expressão lingüística e a capacidade de organização da língua sob a forma de diversos textos que circulam na sociedade. Isso significa que o estudante deve, ao concluir o Ensino Básico, estar apto a produzir, entender, escrever e falar a língua padrão, nas mais diversas situaçóes comunicativas, principalmente sabendo reconhecer quando e como adequar sua expressão às variantes lingüísticas e às situações em que é possível, ou mesmo apropriado, o uso de variantes não-padrão.

\section{Conclusão}

O ensino da língua portuguesa no Cepae-UFG tem sido pautado pelo estudo da língua materna em suas mais diversas manifestações. Nesse sentido, toda atividade de linguagem exercida dentro da escola é orientada pelo uso de habilidades cognitivas que são requeridas para o uso da língua materna em suas variantes escrita e oral, seja no domínio da língua padrão ou da coloquial. É função da escola fornecer aos estudantes uma reflexão acurada dessas instâncias lingüísticas, bem como ajudá-los a reconhecerem os momentos adequados ao uso das manifestaçóes da língua portuguesa. Assim o texto, nas suas mais variadas formas e gêneros, constitui a unidade básica da linguagem verbal e a função comunicativa é o eixo principal do texto e do ato lingüístico.

Ao ensinar ou aprender uma língua é importante ter consciência de que, em qualquer nível, esta se constitui na heterogeneidade, pois é fruto de falantes distintos, inseridos em situações sociais também distintas. Assim também são as regras e os usos de uma língua: um jogo de alternância entre o que é universal e o que é variável, pois a língua é um construto do indivíduo e, também, da coletividade, qualquer homogeneidade que se busque tem como função apenas descrever uma parcela desse universo lingüístico.

Trata-se, então, de observar a língua em uso, em seu momento de construção, evidenciando as mais variadas e criativas maneiras de o falante se expressar em sua língua. É importante refletir sobre o processo pelo qual passam alguns itens como o onde, pois, muitas vezes, a alternância de funçóes 
Revista Solta a Voz, v. 18, n. 2169

semânticas e sintáticas de um item gramatical pode ser fruto de um princípio enraizado em suas origens lingüísticas (cf. Vitral e Ramos, 1999). Assim:

Se a hipótese funcionalista reside no fato de a estrutura gramatical depender do uso que se faz da língua, determinada pela situação comunicativa, pensar a língua e conseqüentemente a gramática implica compreendê-las motivadas pelas circunstâncias e pelos contextos específicos de uso. (Oliveira e Coelho, 2003, p. 106).

Nesse sentido, o ensino de língua portuguesa deve estar atento aos variados níveis de representação e uso da língua. $\mathrm{O}$ importante é demonstrar que o funcionamento da linguagem é um todo e que o ensino de língua, bem como o seu aprendizado, ocorrem em situaçóes reais de comunicaçáo, em que os falantes têm um objetivo a cumprir: produzir sentidos.

Essas reflexóes possibilitam compreender que o professor, mesmo ainda tendo dificuldades em implementar um trabalho cuja percepçáo de linguagem considere a interação como um elemento fundamental da ordem lingüística, tem necessidade de estabelecer uma prática pedagógica ancorada em princípios comunicativos e de ampliar as discussóes acerca do papel da interação lingüística e de seus falantes. Nesse debate, muitos professores sáo levados a (re)construir suas concepções sobre língua, linguagem, gramática, texto, produçáo escrita e oral, conforme afirma Rauber (2005), de modo que o ensino de língua contemple uma proposta de língua contextualizada, que permita ao estudante desenvolver suas habilidades comunicativas e lingüísticas necessárias à sua constituição como cidadão.

No processo de repensar o ensino de língua portuguesa na escola básica estabelece-se não somente um sustentáculo para o desenvolvimento de pesquisas lingüísticas teóricas e práticas, mas, sobretudo, o comprometimento que os profissionais da linguagem têm com o processo de ensinoaprendizagem. Uma orientaçáo de caráter funcionalista e interacional que oriente o trabalho com a língua em uso, em sala de aula, não somente subsidia material de reflexão para o aprimoramento das teorias lingüísticas que se preocupam com a interaçáo comunicativa, como exige uma alteraçáo no modo como professores, escola básica, ensino superior e a própria sociedade entendem o conceito de língua e linguagem. Aos professores, especialmente, resta o trabalho árduo de "filtrar" e aplicar ao ensino aquelas orientaçóes relevantes para a formação do sujeito. 
170 Revista Solta a Voz, v. 18, n. 2

\section{REFERÊNCIAS}

BAKHTIN, M. Marxismo e filosofia da linguagem: problemas fundamentais do método sociológico na ciência da linguagem. 7. ed. São Paulo: Hucitec, 1995.

CASTILHO, A. T. de. (Org.). Para a história do português Brasileiro. v. 1. São Paulo: Humanitas, 1998.

CASTILHO, A. T. de. e JUNGBLUTH, K. (Coords.). Historiando o português brasileiro. História das línguas: variedades, gramaticalização, discursos. (Relatório das atividades desenvolvidas ao abrigo do Programa Capes-Daad-Probral, de 2000 a 2003 (Projeto 109/00)). Blaubeuren, 2003. Disponível em http:/www.alfal.org/Ataliba\%20T.htm.

CHOMSKY, N. Aspectos da Teoria da Sintaxe. Trad. de Eduardo Raposo. 2. ed. Lisboa: Sucessor, 1965.

OLIVEIRA, M. R. de e COELHO, V. W. Lingüística funcional aplicada ao português. In: OLIVEIRA, M. R. de e MARTELOTTA, M. E. Lingüistica funcional: teoria e prática. Rio de Janeiro: DP\&A, 2003. p. 89-121.

CUNHA, A. G. da. Dicionário etimológico. 2. ed. Rio de Janeiro: Nova Fronteira, 1994.

CUNHA, M.A. F. da; OLIVEIRA, M. R. e MARTELOTTA, M. E. (Orgs.). Lingüistica funcional: teoria e prática. Rio de Janeiro: DP\&A, 2003.

DIK, S. The theory of Functional Grammar. Dordrecht: Foris Publications, 1989.

The theory of Functional Grammar - Part 2: Complex and Derived Constructions. Berlin/New York: Mouton Gruyter, 1997.

FERREIRA, L. M. A. Estabilidade e continuidade semântica. In: Linguistica funcional: teoria e prática. Rio de Janeiro: DP\&A, 2003. p. 73-87.

GIVÓN, T. Functionalism and grammar. Amsterdam/Filadélfia: John Benjamins, 1995.

. On understanding grammar. New York: Academic Press, 1979.

HALLIDAY, M. A. K. An Introduction to functional grammar. London: Edward Arnold, 1985. 
As bases funcionais da linguagem. In: DASCAL, M. Fundamentos metodológicos da lingüistica. São Paulo: Global, 1976. p. 125-161.

NEVES, M. H. de M. A gramática de usos do português. São Paulo: UNESP, 1999.

NEVES, M. H. de M. A gramática funcional. Martins Fontes: São Paulo, 1997.

A gramática. História, teoria e análise, ensino. São Paulo: Editora UNESP, 2002.

. Guia de usos do português. Confrontando regras e usos. Sáo Paulo: UNESP, 2003.

PCN. Parâmetros Curriculares Nacionais: introdução aos Parâmetros Curriculares Nacionais. Brasília: MEC/SEF, 1997.

RAUBER, A. L. Interdisciplinaridade e princípios funcionalistas no ensino de lingua portuguesa. 2005. Dissertação (Mestrado em Letras e Lingüística) - Faculdade de Letras, Universidade Federal de Goiás, Goiânia, 2005.

SOUZA, E. H. P. M. A multifuncionalidade do onde e seu uso em Salvador. Salvador: Instituto de Letras. UFBA.(Apresentado para Exame de Qualificação), 2001. Disponível em: < www.prohpor.ufba.br/obsdia.html >. Acesso em: 15 mai. 2006.

VITRAL, L. e RAMOS, J. Gramaticalização de você: um processo de perda de informação semântica? Revista de Filologia e Lingüistica Portuguesa. v. 3. São Paulo: Edusp, 1999. p. 55-88. 